\title{
A obra do sociólogo Pierre Bourdieu: uma irradiação incontestável
}

Ione Ribeiro Valle

Universidade Federal de Santa Catarina

\section{Resumo}

Como todas as grandes produções científicas, a obra do sociólogo Pierre Bourdieu (1930-2002) foi elaborada em torno de uma intuição e construída a partir de idéias-força, formuladas, desenvolvidas, reformuladas, retomadas na maioria de suas publicações - uma intuição fundadora que procura articular alguns conceitos maiores, colocados no centro de sua análise da estrutura do mundo social e das relações sociais. Pierre Bourdieu, que desejou transformar a sociologia numa ciência total capaz de restituir a unidade fundamental da prática humana, atribui-lhe uma função crítica, que implica o desvelamento dos mecanismos educacionais, culturais, sociais e simbólicos de dominação.

Neste trabalho, tentaremos resgatar o caminho sociometodológico proposto e percorrido por Pierre Bourdieu, por meio da elaboração de uma espécie de cartografia de sua obra e da descrição das principais etapas de sua trajetória intelectual e profissional, enfatizando seus engajamentos políticos e sociais. Procuraremos também explicitar o conteúdo de algumas de suas principais obras, sua contribuição para a compreensão das práticas de diferentes campos sociais, destacando seus limites e as criticas que suscitaram. Por último, debruçaremo-nos sobre o aporte da obra de Bourdieu no Brasil, ressaltando sua contribuição ao desenvolvimento de uma importante vertente crítica no campo da Sociologia da Educação, e examinaremos principalmente a presença da reflexão do autor na emergência de uma perspectiva microssociológica no campo da pesquisa educacional brasileira.

\section{Palavras-chave}

Pierre Bourdieu - Sociologia da Educação - Pesquisa educacional Práticas sociais.

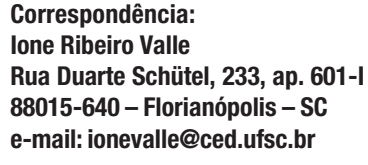




\title{
The work of the sociologist Pierre Bourdieu: an undisputable irradiation
}

Ione Ribeiro Valle

Universidade Federal de Santa Catarina

\begin{abstract}
As every great scientific production, the work of sociologist Pierre Bourdieu (1930-2002) was created around an intuition, and built from strength-ideas formulated, developed, reformulated, and resumed in most of his publications - a founding intuition that seeks to articulate bigger concepts placed at the center of his analysis of the structure of the social world and social relations. Pierre Bourdieu, who wished to transform sociology in a total science capable of restoring the fundamental unity of human practice, attributed to his field a critical function that implies unveiling educational, cultural, social, and symbolic mechanisms of domination.

In the present work we shall attempt to retrace the socialmethodological path proposed and followed by Pierre Bourdieu through the sketching of a sort of cartography of his work, and the description of the main chapters of his intellectual and professional trajectory, emphasizing his social and political commitments. We shall also try to clarify the content of some of his main works, and his contribution to the understanding of the practices in different social fields, highlighting its limits and the criticism it has raised. Lastly, we look into the legacy of Bourdieu's work in Brazil, focusing on his contribution to the development of an important critical movement in the field of the sociology of education, and we examine intently the presence of his reflection in the emergence of a micro-sociological perspective in the field of educational research in Brazil.
\end{abstract}

\section{Keywords}

Pierre Bourdieu - Sociology of education - Educational research Social practices.

\footnotetext{
lone Ribeiro Valle

Ione Ribeiro Valle
Rua Duarte Schütel, 233, ap. 601-I

88015-640 - Florianópolis - SC
}

e-mail: ionevalle@ced.ufsc.br 
Como todas as grandes obras, a sociologia de Pierre Bourdieu (1930-2002) cresceu em torno de uma intuição, uma idéia-força, que ele desenvolveu, repetiu, reformulou e aplicou em diferentes problemáticas, retomando-a na maioria de suas mais de 300 publicações, traduzidas para diversas línguas ${ }^{1}$. Essa intuição fundadora pode ser resumida em uma fórmula única: 'as idéias puras não existem'. Caracterizada por uma abertura sem precedentes da pesquisa sociológica, sua produção teórica abriu horizonte para inúmeras outras abordagens científicas (no campo psicológico, antropológico, etnológico, científico, literário, econômico, cultural).

Em virtude do caráter inovador e multidisciplinar, o pensamento sociológico de Pierre Bourdieu tem influenciado estudos sobre arte, comunicação, linguagem, religião, política e educação. Segundo Thompson (2001), sua obra constitui um esforço excepcional para oferecer à análise do mundo social um quadro teórico coerente, de interesse e de alcance comparável aos trabalhos de pensadores contemporâneos, que desenvolveram concepções muito diferentes.

Intelectual crítico, instigante, capaz de pensar de forma articulada teoria e práticas sociais, Pierre Bourdieu exerce influência não somente sobre os pensadores franceses, mas sobre os intelectuais de vários países, pertencentes a outras disciplinas das ciências humanas e sociais, como o confirma sobretudo sua notoriedade no estrangeiro. Considerado por Ortiz (1994) como 'autor de uma obra se não acabada pelo menos plenamente desenvolvida', ele funda - com ou contra pesquisadores de sua geração - uma nova maneira de fazer sociologia e institui uma perspectiva teórico-crítica radical e original.

\section{Uma experiência fundadora}

Enquanto muitos de seus colegas pensadores evocavam uma sociologia em estado de crise, Pierre Bourdieu reconhece sua importância e acredita que ela pode ser elevada a um alto grau de cientificidade e de objetividade.
Ele considera que essa disciplina possui uma função crítica fundamental, que consiste em desvelar os processos de funcionamento social, especialmente os de dominação. Ele se propõe então, como objetivo último, a transformar a sociologia numa 'ciência total', capaz de restituir a unidade essencial da prática humana. Sua obra pode ser lida de múltiplas formas: como uma análise dos mecanismos de dominação das sociedades modernas, como uma teoria das práticas sociais ou, ainda, como uma análise da produção das idéias e dos sistemas simbólicos.

Pierre Bourdieu desenvolve uma abordagem singular dos fatos sociais, que se institui como um pólo na paisagem sociológica contemporânea e impulsiona o surgimento de uma nova orientação teórica. Preocupado com o estudo da realidade - possível desde que seja ultrapassada - e tendo por fim a 'objetividade social', ele constrói novos conceitos de interpretação, tentando superar a tendência ao isolamento disciplinar e à redução dos processos sociais a estados estáticos, característicos da pesquisa de base positivista. A sociologia é considerada como uma profissão (un métier), o sociólogo deve apreender os instrumentos metodológicos para analisar racionalmente os fenômenos sociais que observa (Bourdieu, 1999).

A fórmula inaugurada por Bourdieu exige do pesquisador certo desligamento ou distanciamento emocional do objeto e lhe impõe um importante desafio: separar as representações imediatas e os prejulgamentos espontâneos do saber científico. A eficiência dessa fórmula, que parte do princípio de que as práticas sociais resultam de uma cadeia complexa de ações (nem sempre conscientes) de longa duração, supõe primeiramente a revisão das categorias científicas mais habituais e dos recortes teórico-metodológicos mais tradicionais. Em seguida, a reaproximação de objetos diversos e de especializações disciplinares distintas.

1. A vasta obra de Pierre Bourdieu compreende mais de 40 títulos, além de algumas publicações importantes, como a Revue Actes de la Recherche en Sciences Sociales (que se define como revista-manifesto e visa a construção de um novo pensamento sociológico) e a coleção Raisons d'Agir (palavra de ordem que salienta a necessidade de ter razões para agir, razões racionais, elaboradas, construídas). 
A problemática teórica proposta por Pierre Bourdieu constitui-se num esforço sistemático para transpor uma série de contraposições e de antinomias, que embaraçam as ciências sociais desde seu início: indivíduo contra sociedade, ação contra estrutura, liberdade contra necessidade. Sua abordagem metodológica, denominada de conhecimento praxiológico, busca superar um dilema clássico do pensamento sociológico, alicerçado nas discordâncias entre duas perspectivas de investigação empírica, consideradas inconciliáveis: o subjetivismo (pressupõe a possibilidade de apreensão imediata da existência vivida do outro e entende que essa apreensão se constitui num modo mais ou menos apropriado de conhecimento do mundo social) e o objetivismo (pressupõe uma ruptura com a experiência imediata, o que implica colocar entre parênteses a primeira experiência do mundo social e elucidar as estruturas e os princípios, inacessíveis a toda apreensão imediata, sobre os quais repousa essa experiência).

Pretendendo contornar essas oposições, Bourdieu desenvolve sua teoria da prática, que visa ultrapassar o objetivismo sem cair no subjetivismo, levando em consideração a primeira condição à cientificidade da pesquisa sociológica, qual seja: a ruptura com a experiência imediata. 0 autor reconhece que essa ruptura não é fácil, pois os pesquisadores em ciências sociais participam diretamente de um determinado mundo social (grupo ou classe), estando envolvidos por uma determinada linguagem, por conceitos e valores comuns da vida cotidiana.

Apesar de rejeitar a 'etiquetagem' e não possuir nenhuma simpatia pelo que considerava como uma espécie de 'maneirismo intelectual', seu nome aparece freqüentemente associado à abordagem holística ou ao estruturalismo genético. Todo pensamento de Bourdieu vai consistir em 'desnaturalizar o mundo social', propondo-se a desvelar as regras do jogo intelectual, dos cientistas, dos pensadores, dos políticos, dos educadores.

Sociólogo polêmico, cuja obra suscitou distintas apropriações, apesar de seu desejo de construir um fio condutor único, Pierre Bourdieu tornou-se uma figura emblemática na luta contra o neoliberalismo, por tecer críticas profundas a intelectuais, 'experts', jornalistas, 'ensaístas de corte' que, pela difusão dos mecanismos de mundialização, participam da edificação de um mundo dominado pela ideologia neoliberal. Figura carismática, Bourdieu é considerado um dos principais cientistas do mundo, permanecendo objeto de uma verdadeira adoração por parte de estudantes e pesquisadores das ciências humanas.

Segundo Lahire (2002), Bourdieu deixa como legado intelectual um verdadeiro 'tesouro sociológico’, que reúne esquemas interpretativos múltiplos, extraídos do conjunto do patrimônio internacional de ciências humanas e sociais. Sua reflexão transgrediu as fronteiras que separam (tanto no âmbito das instituições quanto das representações) o campo da psicologia do campo da sociologia, a esfera mental (ou psíquica) da esfera social, o individual do coletivo.

Em virtude da complexidade e da amplitude da obra de Bourdieu, Lahire propõe uma espécie de 'fidelidade crítica', capaz de assegurar uma adequada apropriação dessa preciosa herança, que consiste na aplicação 'infinita' de sua teoria em novos campos. Essa aplicação testemunha a continuidade de suas interrogações e de sua vontade permanente de testar seus conceitos em análises de inúmeros objetos e de múltiplos campos sociais. Lahire ressalta ainda que seu esforço teórico poderá ser '(mal)tratado' se predominar a ignorância e o desdém de um lado e a adoração ingênua de outro.

Para Lahire (2002), Bourdieu era um pedagogo extraordinário que, além de aportar um saber teórico que insistia na importância da relação prática com a teoria e de rejeitar "a arrogância do sociólogo que recusa sujar as mãos na cozinha da empiria" (Bourdieu, 1979, p. 598), ensinou-nos o modo de aplicação do que dizia. Ele fez um apelo à mobilização das mais sofisticadas ferramentas teóricas, visando apreender os objetos concretos ou socialmente considerados como menores, além de evocar permanentemente uma ascese do trabalho científico e exigir seriedade e rigor na construção do objeto e da pesquisa. 
Deve-se, portanto, evitar a utilização simplificada - e simplista - de seus conceitos e de sua terminologia, dando a impressão de que nada se faz a não ser pôr a máquina de produzir textos para funcionar. Parece gozar de amplo consenso a idéia de que o melhor tributo que se pode prestar a Pierre Bourdieu consiste em buscar inspiração na sua herança teórico-empírica, de forma rigorosa e crítica.

\section{Uma trajetória original}

\section{Da origem 'modesta' à posição ‘dominante’}

A trajetória de um cientista, como de todo agente social, é caracterizada pelo conjunto de propriedades ligado à sua posição no espaço social. A análise da trajetória de um autor não se reduz portanto a um exercício de estilo, sobretudo em se tratando de Pierre Bourdieu, mas requer a utilização dos mesmos princípios científicos aplicáveis a um outro estudo sociológico. Os elementos biográficos permitem levar em consideração as propriedades objetivas do autor, pois suas construções epistemológicas, assim como suas tomadas de posição - dogmáticas ou caricaturais -, provêm de uma mesma origem. Esta pode fornecer elementos fundamentais para explicar as práticas produzidas no decorrer da história individual e coletiva.

As raízes do pensamento de Pierre Bourdieu podem ser encontradas numa dolorosa, mas rica e diversificada experiência existencial, reconhecida pelo próprio autor. 0 distanciamento em relação ao mundo intelectual e o fato de ser constantemente lembrado de seu 'estrangeirismo' lhe permitiram ‘ver o que outros não vêem' e o incitaram a sentir o que outros não sentem: os códigos implícitos, as rotinas, os fundamentos que governam o mundo das idéias e orientam as práticas cotidianas.

Nascido em $1^{\circ}$ de agosto de 1930 numa pequena cidade francesa (Denguin), situada na Região do Béarn (Departamento dos PirineusAtlânticos), onde seu pai ocupava o posto de funcionário da agência de correios, Bourdieu se confrontou muito cedo com os obstáculos impostos aos jovens das classes desfavorecidas para levar adiante seus estudos. Beneficiário de uma bolsa de estudos, o jovem bearnês (cujo sotaque provocava riso entre os colegas) realizou seus estudos, primeiramente, no liceu de Pau (que marcou sua memória pela experiência vivida num 'edifício fechado, com corredores desertos e com ecos assustadores, onde se debatia para afastar a fatalidade de suas origens'), freqüentou em seguida o prestigioso Liceu Louis Le Grand em Paris e, finalmente, a reputada Escola Normal Superior, destinada à formação da elite intelectual francesa.

Ainda que tenha conseguido galgar os mais altos degraus da hierarquia escolar e científica, Bourdieu nunca se mostrou à vontade no interior da intelectualidade francesa e confessou com freqüência ter tido muitas dificuldades para se desembaraçar de seu 'sentimento de ilegitimidade'. Seu pensamento e a maneira de se expressar passavam permanentemente por um esforço de autocontrole, uma luta contra si mesmo e contra seu meio de procedência, explicitando uma enorme distância entre o mundo de origem e o mundo intelectual, que valoriza o dom da fala, o espírito ágil e as tiradas fáceis. Ele revelou, em várias oportunidades, não gostar do que havia de intelectual nele, seja em relação à autoridade da qual estava investido, conseqüência da lógica da consagração escolar, seja em relação à necessidade de falar com autoridade, o que sempre foi um grande dilema para ele. Além disso, Bourdieu admitia enfrentar uma espécie de 'vergonha social', que lhe parecia análoga ao sentimento experimentado pelos homossexuais no interior de uma ordem instituída que os exclui. Para ele, a vergonha endurece os caracteres e provoca uma vontade imensa de compreender e de denunciar.

\section{Da filosofia à antropologia}

Para compreender a trajetória universitária e profissional de Pierre Bourdieu e principalmente sua conversão da filosofia para a sociologia, é necessário observar a configuração do campo intelectual durante os anos de sua formação. 
Nos anos 1950, o campo filosófico apresentava-se dominado pelo existencialismo. No entanto, após a Segunda Grande Guerra, a referência existencialista - sobretudo sob a forma sartriana - deixava progressivamente insatisfeitos os jovens filósofos, em particular os egressos da Escola Normal Superior. Rejeitar a história (ou a cultura) dessa instituição parecia fundamental à maioria desses jovens, na medida em que a filosofia, como especialidade predominante, parecia-lhes puramente ascética e desprovida de uma verdadeira função teórica. Além disso, a conjuntura universitária se mostrava totalmente favorável ao questionamento dos modelos acadêmicos em vigor. A ampliação de vagas para enquadrar um público crescente, as novas oportunidades geradas por programas especiais (de bolsas de estudo por exemplo), a diversificação dos modelos de seleção, o desenvolvimento do ensino das disciplinas das áreas humanas e sociais, assim como o reforço das instituições de pesquisa e de erudição, que marcaram as mudanças no sistema de ensino francês, favoreceram o aparecimento de novos estilos intelectuais, distintos da tradição racionalista e histórica.

As transformações do Ensino Superior produzem claramente suas conseqüências nos anos 1960. 0 acesso a uma posição universitária se torna menos dependente das imposições características da 'ordem de sucessão', que garantia a reprodução da identidade dos detentores de postos por meio da seleção dos candidatos à sua sucessão. Essa conjuntura gerou uma nova atmosfera intelectual, que aparentemente parecia facilitar e valorizar a criatividade e a originalidade. Em virtude disso, muitos filósofos sentiram necessidade de romper com a imagem de amadorismo e verbalismo, associada ao existencialismo em declínio, e compreenderam que a ciência não podia mais permanecer longe dos problemas sociais e políticos, reduzindo-se a uma simples manipulação instrumental. Essa conjuntura abre espaço para o estruturalismo e a epistemologia, movimentos intelectuais que evoluem paralelamente, por terem suas gêneses em refutações semelhantes, e se impõem rapidamente aos intelectuais franceses dos anos 1960.

Pierre Bourdieu se formou no meio parisiense dos anos 50 e início dos anos 60 do século XX e pertence, portanto, à geração (representada principalmente por Lévi-Strauss, Althusser e Foucault) que se constitui contra o existencialismo dominante no campo intelectual e se opõe à filosofia sem sujeito, ao subjetivismo, ao objetivismo, ao humanismo existencialista, ao personalismo anti-humanista. Ele soube aliar o rigor do método científico com a criatividade do artista e se consagrou ao trabalho incansável da pesquisa, no qual investiu uma libido sciendi sem fim nem fundo. 0 resultado desse engajamento é a produção de uma cultura teórica incomparável, que combina autores cuja tradição canônica procurou opor, adaptando-os e retrabalhando-os conforme as necessidades concretas das análises sociais, a saber: Durkheim e Weber, Marx e Mauss, Cassirer e Wittgenstein, Husserl e Lévi-Strauss, Bachelard e Panofsky, por exemplo.

É nesse contexto que Pierre Bourdieu se distancia da filosofia para abordar um vasto campo das ciências sociais. Sua formação filosófica está marcada por uma dupla herança: a história das ciências (tendo como referência Gaston Bachelard e George Canguilhem) e a fenomenologia (segundo a versão de Husserl e Merleau-Ponty), que entrou em crise no final dos anos 1950. Bourdieu, assim como Foucault (que apesar de suas poucas confidências revela um mal-estar em relação à norma, à cerimônia, à representação, à tagarelice, à cena oficial) e Derrida, testemunha essa crise e a necessidade emergente de inventar algo diferente, de investir numa outra direção.

No entanto, Bourdieu se mostra igualmente atraído pela perspectiva desenvolvida por Lévi-Strauss. Ele acompanha de perto a evolução da sua obra e acaba adotando certos aspectos de seu método, principalmente no que concerne à importância concedida à análise das relações e das oposições, presente em seus primeiros estudos etnográficos. Originária da 
filosofia, a etnologia permitia uma reconversão legítima, graças à sua posição estrutural, podendo funcionar como uma ligação intermediária entre filosofia e sociologia.

A obra de Weber também inspirou Pierre Bourdieu, que se interessou pela maneira em que os grupos aparecem nos diferentes campos e lutam pelo poder e para ampliar sua influência. Segundo Kalinovski (2003), não se trata de explicitar a forma de apropriação da obra de Weber por Bourdieu, mas de evocar, segundo modalidades distintas, a reação contrária à instituição ou às instituições universitárias e ao papel social dos intelectuais em geral. Bourdieu atribuiu, freqüentemente, à sua origem e à sua estadia na Algéria tanto a decisão de se afastar da filosofia para fazer sociologia, quanto sua crítica à postura escolástica, considerada como tributária de uma posição em relação ao mundo acadêmico. 0 que surpreende na sua obra é o contraste exacerbado entre a monumentalidade erudita que se afirma, as distinções sutis que ele opera entre os fenômenos ou doutrinas que parecem inacessíveis aos não-eruditos e o caráter abertamente político de suas definições concernentes ao sistema de domesticação das massas, característico das sociedades dominadas por intelectuais. Enquanto Bourdieu se mostra altamente provocador em relação a esse grupo social, que se beneficia economicamente, Weber refere-se ao uso específico que é feito do poder intelectual. Longe de descrever essa sociedade dominada pelos intelectuais como uma sociedade esclarecida, Weber insiste no fato de que, para se perpetuar, esse poder permanece monopólio de um único grupo social excludente dos demais. Os intelectuais são vistos por essas perspectivas como preocupados, antes de tudo, em manter privilégios que lhes garantam o acesso à dominação social. Weber vê justamente na autonomia dos intelectuais a condição de eficácia máxima de sua heteronomia, o que permite oferecer ao soberano, mas também aos grupos sociais mais favorecidos, os serviços de legitimação que apresentam a melhor atuação. Bourdieu reconstituiu o sistema de Weber analisando o princípio gerador desse sistema e desvelando a maneira pela qual se efetivava a relação entre dominantes e dominados.

Sua abordagem também não se identifica com o tipo tradicional de análise marxista que considera os fenômenos políticos como simples manifestação dos processos socioeconômicos ou das relações e oposições entre as classes. As análises marxistas vêem o mundo social como um espaço unidimensional, onde tudo é orientado e conduzido, direta ou indiretamente, em função do modo de produção econômica e das contradições dele geradas. Para Bourdieu, o mundo social é um espaço multidimensional, que não pode ser reduzido a um determinismo econômico de classe, pois se apresenta diferenciado em campos relativamente autônomos, no interior dos quais os indivíduos ocupam posições determinadas. Segundo Thompson (2001), ele emprega de maneira distinta a noção de classe em relação aos marxistas tradicionais, não a definindo como simples oposição entre proletários e não-proletários, mas como conjuntos de agentes que ocupam posições análogas no espaço social, possuem quantidades similares de capital, oportunidades semelhantes de sucesso e disposições muito próximas.

Para Pinto (2003), a exemplo do que fizeram Derrida e Foucault, Bourdieu expõe uma maneira de sair da via ortodoxa universitária e intelectual e propõe uma nova relação com a cultura, com a filosofia, portadoras de autoridade, mas também de censura intelectual. 0 que os aproxima é o esforço de desconstruir certos pressupostos intelectuais ou, mais precisamente, de replicar a autoridade intelectual como forma de autoridade social. Bourdieu é o que assume melhor a produção de um discurso sobre si, respondendo a três exigências: uma ética, que implicou testar em si mesmo a pertinência dos instrumentos de análise; uma socioanalítica, que procurou compreender o que as tomadas de posição devem às pulsações sociais; uma político-intelectual, que consistiu em incitar, pela virtude do exemplo, os pesquisadores a fazerem mais do que 'contar histórias'.

A obra de Pierre Bourdieu, que ele sempre considerou como resultado de um esforço 
coletivo, contribuiu para reaproximar sociologia e história. Para tanto, ele procurou incitar a sociologia a integrar a história nas suas abordagens, por entender que a oposição entre passado e presente é arbitrária e por acreditar que a história se inscreve no corpo sob a forma de habitus, manifestando-se tanto no estado objetivo (máquinas, monumentos, livros, teorias) quanto no estado incorporado (sob a forma de dispositivos).

Bourdieu expõe, com um constrangimento nem sempre contido e freqüentemente assumido, um ponto de vista intelectual crítico. Segundo ele, os intelectuais não estão mais na vanguarda, como se pensava antes, pois não se mostram preparados para intervir no mundo atual, nem por formação nem por disposição. Eles colaboram passivamente com as forças econômicas e políticas dominantes, parecendo controlados por uma espécie de 'aristocratismo profissional', que os desvia das questões triviais da vida cotidiana e das realidades sociais e econômicas. Ele reconhece, no entanto, que está cada vez mais difícil acumular competências múltiplas (econômicas, sociológicas, históricas, políticas), indispensáveis à compreensão do mundo e à antecipação das conseqüências futuras. 0 intelectual crítico que o mundo de hoje requer deve ser coletivo e profissional.

São portanto os filósofos, símbolos do 'pensamento puro e da inteligência arrogante', os primeiros alvos de Pierre Bourdieu. A maioria dos seus livros faz uma crítica profunda à chamada 'razão pura'. Enquanto a filosofia alemã tentava explicar o sentido do belo, do bom ou do mau gosto pessoal por um julgamento transcendental e subjetivo, ele procura mostrar que o gosto é uma construção social e que está ligado à posição ocupada num determinado campo, sendo revelador de maior ou menor prestígio. Bourdieu se apóia numa análise dos julgamentos estéticos para construir uma teoria social que repousa sobre a idéia de que os indivíduos e os grupos existem somente numa relação de distinção entre si. As entidades lingüisticas, as propriedades sociais, individuais ou coletivas não têm sentido em si mesmas, mas somente numa estrutura racional e hierárquica, que não cessa de se modificar e de se deslocar: 'Ainda que os conteúdos mudem, a diferença, isto é, a hierarquia e a dominação continuam intactas'. Ele parte da idéia de que as pessoas emitem juízos de valor - como, por exemplo, 'detesto música sertaneja' - para se diferenciar dos que ocupam posições hierarquicamente inferiores.

\section{O espírito científico colocado a nu ou a inscrição social das idéias}

A característica principal da teoria social de Pierre Bourdieu consiste na sua não-inscrição nas correntes sociológicas tradicionais. Ele se situa, como pudemos ver, num contexto em que o pensamento científico se fundamenta em múltiplas abordagens e não mais por uma disciplina unificada e empenha-se em combinar diferentes perspectivas teóricas no campo conceptual. Uma outra característica de sua obra é o fato de que a perspectiva crítica se apresenta muito desenvolvida, estando marcada por uma profunda convicção política resultante de uma constatação científica: não se pode mais explicar o mundo social a partir de antigos e rígidos modelos teóricos.

A construção teórica de Bourdieu é precedida por uma sucessão de críticas explícitas, endereçadas principalmente ao estruturalismo (rejeitado em sua forma extrema em razão da redução objetivista, que nega a prática dos agentes e retém as imposições estruturais); ao interacionismo (recusado por considerar que os agentes não são portadores de nenhuma determinação social e por omitir a gênese social); ao subjetivismo (rejeitado por forjar o mito de um sujeito sem história e sem determinantes); à fenomenologia (por vê-la como exclusivamente descritiva, constituindo-se somente numa etapa da pesquisa).

Pierre Bourdieu não se inscreve igualmente nos diferentes pólos sociológicos da França contemporânea e desenvolve uma crítica importante aos pressupostos teóricos ou aos métodos de investigação utilizados por esses pólos: 
1. 0 individualismo metodológico de Raymond Boudon, apoiado sobretudo no pensamento de Tocqueville e de Weber, é criticado por sua visão redutora dos atores sociais. Esse paradigma explica um fenômeno social qualquer como resultado de um conjunto de comportamentos individuais e, portanto, produto da agregação das ações individuais, além de postular que a lógica dessas ações deve ser procurada na racionalidade dos atores, no sentido análogo àquele empregado pelos economistas neoliberais.

2. A abordagem estratégica de Michel Crozier, que tem por objetivo principal a análise das relações de poder nas organizações, mostrando que os atores - racionais, mas portadores de uma racionalidade limitada - dispõem de uma margem de liberdade que é o fundamento do poder, a qual interfere na maximização dos resultados da empresa ou da administração.

3. A sociologia da ação, de Alain Touraine, centrada na análise dos movimentos sociais e seu papel decisivo na mudança social.

4. A sociologia política também é objeto de suas crítica por perpetuar a ideologia da democracia, ensinada nas instituições com a finalidade de formar os quadros de pessoal do Estado, ignorando os limites e dissimulando as conseqüências das ações efetivadas em nome do ideal democrático. Nesse sentido, todos os campos da sociologia podem contribuir para a legitimação da ordem existente, fornecendo argumentos utilizados pelos dominantes para manterem sua dominação.

Segundo Sapiro (2003), Bourdieu reteve de sua formação filosófica a desconfiança em relação às explicações mecanicistas, de base behaviorista, que procura os fundamentos fisiológicos do comportamento ou fundamentada na análise estruturalista, que reduz as condutas a simples execução mecânica de uma regra. Contrapondo-se à visão mecanicista do estruturalismo e do marxismo, que faz dos agentes simples suportes das estruturas ou executores de regras e de uma função específica, Bourdieu reintroduz a 'concepção finalista', importante para a fenomenologia, que descreve as condutas como sendo orientadas na direção de determinados fins. Ele recorre também à noção de estratégia, utilizada pela sociologia interacionista (principalmente por Goffman), visando restituir uma margem de invenção e de improvisação nos agentes. Ademais, Bourdieu transpõe para a sociologia a noção chomskyana de 'competência generadora'. No entanto, diferentemente de Chomsky que a considera como inata, ele a concebe como geradora das condutas, sendo portanto adquirida. Produto da aprendizagem, os esquemas de percepção e de ação concebem as condutas sob a forma de disposições.

Contra a maioria dos sociólogos de seu tempo, Pierre Bourdieu propõe o que chama de estruturalismo construtivista. Por estruturalismo, quer dizer que existe no mundo social, e não somente nos sistemas simbólicos, linguagens, mitos, estruturas objetivas, independentes da consciência ou da vontade dos agentes, capazes de orientar ou de impor suas práticas ou suas representações. Por construtivismo, entende que há uma gênese social tanto nos esquemas de percepção, de pensamento e de ação, quanto nas estruturas sociais.

\section{Representante de uma nova 'abordagem sociológica'}

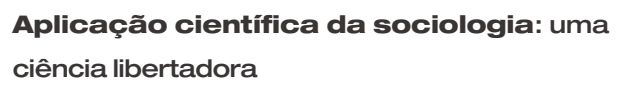

Bourdieu expõe as grandes linhas de uma abordagem distintiva do fenômeno político, cujas implicações metodológicas estão bem presentes: é superficial analisar os discursos e as ideologias políticas enfatizando os enunciados, sem considerar a constituição do campo político e a relação entre esse campo e o espaço social mais amplo, o qual abrange as posições e os processos sociais. Ele chama a atenção para a exigência de fundar toda análise do discurso político na construção do campo, no interior do qual esse discurso é produzido e recebido, e observar as organizações distintivas, 
seus esquemas de produção e de percepção e as relações mantidas com o espaço social no seu conjunto.

Os avanços científicos mais marcantes, impulsionados por Pierre Bourdieu, podem ser observados em diferentes domínios: nos trabalhos sociológicos da cultura, incluindo a sociologia das instituições escolares e universitárias, numa sociologia da arte que se desenvolveu desde os anos 1960, nos estudos referentes ao consumo cultural, numa sociologia da educação, dos bens simbólicos, dos grupos sociais, das classes de idade.

Segundo Thompson (2001), os estudos de Bourdieu procuram mostrar que a linguagem é um fenômeno sociohistórico e que as trocas lingüísticas compõem as atividades práticas e possuem, portanto, uma dimensão sociohistórica. A elaboração de manuais de gramática, de dicionários e de um corpo de textos exemplificando o uso correto da cultura escrita é a manifestação visível desse processo de normalização progressiva. Enfatizando os aspectos institucionais do uso da linguagem e explorando-os com uma inteligência sociológica aguda, Bourdieu define os aspectos fundamentais das condições sociais de seu uso, ainda ausentes na literatura sobre os atos da linguagem.

Reconstituindo com cuidado o campo lingüístico e estudando de perto certas estratégias dos indivíduos face às circunstâncias formais ou oficiais, Bourdieu observa que as classes superiores estão dotadas de um habitus lingüístico que lhes permite enfrentar com mais tranqüilidade tais circunstâncias. As classes inferiores, cujas condições de existência estão menos propícias à aquisição de um habitus que coincida com os mercados oficiais, além de valorizar pouco esses produtos lingüisticos, se mostram bem menos preparadas para encarar essas situações.

Pierre Bourdieu não negligencia o fato de que os indivíduos estão predispostos, em virtude do habitus, a agir de certa maneira, a perseguir determinados objetivos, a cultivar certas preferências. 0 gosto, por exemplo, não é visto apenas como fruto da subjetividade, mas decorre de uma 'objetividade interiorizada', pressupondo 'esquemas generativos', que orientam e determinam a escolha estética. $\mathrm{Na}$ medida em que os sistemas de classificação são engendrados pelas condições sociais e que a estrutura objetiva de distribuição dos bens materiais e simbólicos se dá de forma desigual, toda escolha tende a reproduzir as relações de dominação, certos estereótipos e as posições ocupadas num determinado campo.

A tomada de consciência em relação ao papel reprodutor do sistema escolar é muito recente. A tradição libertária do movimento operário (em sua vertente marxista) conserva uma grande veneração pela educação e pela cultura. Veneração considerada legítima por Bourdieu, mas que infelizmente introduz uma espécie de reverência simplória (relativamente consensual entre os intelectuais e artistas), fazendo esquecer que a ciência e a arte são universais, mas que existem pessoas, grupos ou classes que têm o monopólio do universal. A obra de Bourdieu torna-se, portanto, fundamental para o desenvolvimento de uma 'sociologia da educação crítica', capaz de romper com o ciclo do 'otimismo pedagógico', ainda predominante no sistema educacional, sobretudo nos discursos oficiais.

Todo o sistema escolar está construído para identificar e reificar a inteligência, valorizar o dom e a vocação: inteligentes, dotados e vocacionados têm acesso à ciência e à cultura e serão bem-sucedidos na escola e fora dela; os demais devem acomodar-se nas habilitações sem prestígio, ocupar as funções inferiores e contentar-se com as posições subalternas (adequadas para os que não conseguiram chegar aos níveis mais elevados da pirâmide escolar). Segundo Bourdieu, a escola e a família lembram repetidamente que é necessário obter títulos escolares para não ficar desempregado ou para preencher os cargos mais prestigiados e melhor remunerados, o que não é totalmente falso, mas esse fato não pode implicar uma justificação da ordem estabelecida. De maneira talvez mais decisiva, em razão da implantação de um sistema educativo 
estandardizado e independente das variações regionais e com a unificação de um mercado de trabalho onde as posições administrativas dependem do nível de instrução, a escola acaba aparecendo como o principal meio de acesso ao mercado de trabalho, principalmente nas regiões pouco desenvolvidas e menos industrializadas.

No entanto, o sistema escolar produz sofrimentos terriveis, profundos, não reconhecidos porque são admitidos e legitimados: uns se sentem infelizes porque não obtiveram da escola aquilo que esperavam ou, se tiveram sucesso na sua escolaridade, é a sociedade ou o mercado de trabalho que os decepciona; outros porque são excluídos ou fracassam na escola, atribuindo a si mesmos a responsabilidade por seu percurso escolar. A escola está revestida de uma aparência meritocrática, totalmente dissimulada pela ação pedagógica, pela autoridade pedagógica, pelo trabalho pedagógico e pelo sistema de ensino, geradores portanto da violência simbólica. Bourdieu procura demonstrar como se dá a adesão dos agentes sociais à ordem estabelecida e como o sistema de ensino está implicado nessa adesão, nessa cumplicidade impensada, pré-reflexiva, incorporada pelas formas de seleção e classificação, sancionadas e reproduzidas pela escola.

\section{Crítica à dissociação entre trabalho sociológico e engajamento pessoal}

Durante muito tempo Pierre Bourdieu evitou a postura de intelectual militante nos moldes de Sartre (intelectual 'total', que se apresenta em todas as frentes, mas dispõe apenas das armas da especulação filosófica). Segundo Bourdieu, a sociologia deve evitar a tentação do profetismo, que implica a pretensão em encontrar soluções para os problemas sociais, impostas do exterior (como a delinqüência, o fracasso escolar, os conflitos organizacionais).

Com a profissionalização da sociologia, os sociólogos se tornaram dependentes dos que encomendam estudos sociológicos: o risco consiste em impor problemáticas ou, até mesmo, quadros conceituais, que revelam a submissão a uma demanda social, que poderá ser fictícia. Nesse caso, o sociólogo se torna prisioneiro das expectativas, dos conflitos ideológicos, de investimentos sobre pesquisas que servem para designar, nomear, normalizar o mundo social e impor seus pontos de vista.

Essa preocupação com a autonomia da reflexão sociológica e a exigência de objetividade científica não significa um desinteresse ou uma indiferença em relação às questões sociais; ao contrário, conduz à afirmação da vocação política da sociologia, colocando-a a serviço dos dominados. Nesse sentido, os trabalhos de Pierre Bourdieu aparecem como eminentemente políticos e conduzem à redefinição da ação política, do sentido do político e do uso político da sociologia. Trata-se portanto de sair da concepção ainda corrente e talvez predominante - de ciência neutra e de ideologia política, permitindo uma apropriação política do trabalho sociológico: 'a sociologia deve possibilitar o desvelamento das estratégias de dominação'.

Descrevendo o campo social como espaço de conflito, onde os agentes dominantes procuram reproduzir suas condições de dominação, o sociólogo se impõe uma dupla tarefa: realizar um trabalho científico com fortes implicações políticas e se confrontar com todos os agentes sociais que, conscientemente ou não, concorrem para a manutenção da ordem existente, a saber: os intelectuais, os jornalistas, os funcionários das instituições públicas.

Assim, ainda que a sociologia tenha por finalidade primeira o conhecimento e não a ação, pode fornecer instrumentos de compreensão do mundo social e preparar os agentes para lutar contra as várias formas de dominação. É função da sociologia contribuir para uma ação efetiva de emancipação, por meio do estudo das representações do mundo social e da elucidação do caráter arbitrário de certos esquemas de pensamento, difundidos e reproduzidos historicamente. 0 papel do sociólogo é divulgar o que está vendo, percebendo, constatando, pensando, comprovando pelos estudos, 
realizados com o apoio do aparelho estatístico disponível. É fundamental que as constatações decorrentes dos discursos científicos produzidos sejam traduzidas numa linguagem menos científica, tornando-se acessiveis a todos.

Essa nova vocação da sociologia está baseada numa definição particular da atividade política: os campos são espaços de produção simbólica, nos quais os agentes encontram-se em luta permanente para infundir as categorias de (di)visão do mundo social. Essa luta simbólica visa à produção de sentidos comuns e revela a posição específica do Estado, que dispõe do monopólio da dominação legítima e, dessa forma, procura inculcar uma definição legítima do mundo social. Em conseqüência, ele detém também o monopólio da violência simbólica, que permite assegurar a dominação dos dominantes, efetivando-a pelo emprego de instrumentos legítimos, que se tornam eficazes porque repousam sobre a negação e dissimulação da dominação.

Bourdieu nomeia não apenas os responsáveis pela eficiência dos mecanismos de reprodução social, mas também os que considera como cegos: primeiramente os homens políticos, que não sabem intervir na sociedade e contribuem para transformá-la no pior; em seguida, a mídia, que acaba por descrever ou colocar em cena menos a realidade social do que seu olhar miserável sobre ela. Os políticos não estão preparados para discutir os problemas sociais e quando o fazem é tarde demais: tudo se decide nos bastidores das comissões e dos comitês, longe dos cidadãos. A mídia, assim como o fazem outros grupos dominantes, tenta impor sua representação subjetiva como representação coletiva.

Pierre Bourdieu lembra que 'o que a história faz, a história pode desfazer'. Assim, expondo aos agentes sociais os efeitos da dominação, a sociologia fornece argumentos mobilizáveis na ação política. A descrição das relações sociais não se reduz à simples demonstração científica, mas se constitui num instrumento de libertação dos dominados, contribuindo para que possam apoderar-se de seu próprio destino. Nesse sen- tido, a sociologia pode tornar-se um contrapoder e favorecer a democracia, pois ela opõe uma contraviolência simbólica ao poder simbólico.

\section{Um engajamento individual militante}

Bourdieu se engaja intensamente nas teorias políticas normativas, mas não procura formular programas políticos. No entanto, suas revelações implacáveis da natureza do poder e dos privilégios, dissimulados sob formas variadas e sutis, e a atenção dispensada ao caráter teórico-prático dos agentes que constroem o mundo social dão às suas obras uma carga crítica implícita. Para ele, a sociologia, mesmo a mais crítica, é lida principalmente pelos dominantes, que se servem dela para fazer uma espécie de demagogia racional, sendo utilizada como instrumento não apenas de justificação, mas sobretudo de arranjo das técnicas de dominação.

Como toda grande obra, o pensamento de Pierre Bourdieu oferece elementos essenciais para pensar o mundo social. Como vimos, a sociologia não pertence a Pierre Bourdieu, mas sua obra pertence à tradição sociológica. Propondo-se a 'pensar a política sem pensar politicamente', Bourdieu procurou demonstrar que, longe de se opor, as ciências sociais e o militantismo podem constituir duas faces de um mesmo projeto, pois analisar e criticar a realidade social permite contribuir para sua transformação.

As modalidades de intervenção política de Pierre Bourdieu se modificam consideravelmente desde o início de 1990. Ao engajamento científico, vem juntar-se um militantismo pessoal, que conduz à multiplicação das formas de ação - inicialmente como testemunha não apenas do sofrimento social, mas também do sofrimento individual (freqüentemente imperceptível, resultante do desequilíbrio das relações entre os indivíduos). Ele põe em evidência a 'miséria de condições' (sofrimentos horizontais, de condição, próprios de uma classe ou grupo) e a 'miséria de posições' (sofrimentos verticais que, no interior de uma mesma categoria, grupo ou classe, atingem os indivíduos situados nos níveis 
mais baixos da hierarquia ou num lugar que não corresponde às suas expectativas).

A fronteira social entre "miséria de situação' e 'miséria de posição', desenvolvida na obra Miséria do mundo (Bourdieu, 1993), é ínfima: no mundo social, existem sofrimentos que não são levados a sério. Eles podem desencadear outros sofrimentos e interferir de forma inesperada no plano político. Essa obra, que pode ser lida como um ato político (no sentido dado por Durkheim aos procedimentos sociológicos na sua totalidade: constituir um saber 'reflexivo' que permita à sociedade intervir nela mesma), é fruto de uma coleta de relatos de vida, sob a forma de entrevistas, estando mais próxima da literatura ou do jornalismo que de uma análise científica. Seu objetivo é aprofundar os conceitos e testar a coerência dos instrumentos da sociologia crítica: "o que o mundo social fez, o mundo social, armado desse saber, pode desfazer'.

Nessa obra, os sofrimentos silenciosos, individuais e conseqüentemente sociais, alguns mais agudos, outros novos, que em geral a miséria impede de exprimir, é que têm a palavra. A aposta é oferecer à sociologia uma 'capacidade' que as outras ciências humanas não têm: 'exprimir e tornar visíveis as misérias de posição’, não apenas os sofrimentos horizontais, mas também os sofrimentos verticais. A intenção dos pesquisadores (coordenados por Bourdieu) foi fazer o que faz todo (bom) jornalista: ver, escutar, observar diretamente e, então, formular questõeshipóteses, baseadas num conhecimento teórico e prático da pessoa interrogada e das condições sociais, das quais ela é o resultado.

Em seguida, Bourdieu mostra uma forte tendência a passar da reflexão à ação. Reclamando por uma sociologia mais ativa, vai às ruas $\mathrm{e}$ protesta contra as ameaças, cada vez maiores, da política de mundialização, que se torna seu principal cavalo-de-batalha. Ele está convencido de que há uma correlação entre as políticas neoliberais e as taxas crescentes de delinqüência, entre as políticas neoliberais e as taxas de criminalidade, entre as políticas neoliberais e to- dos os sinais do que Durkheim chamou de anomia. Ele não se refere a essas políticas como se tratasse de um processo natural, pois elas foram engendradas por pesquisadores e tanto sua produção quanto sua difusão foram mantidas em segredo. A principal questão para Bourdieu é saber se os que antecipam as conseqüências funestas da mundialização, apoiados num saber científico, devem também permanecer silenciosos. Ele não permaneceu.

Para Bourdieu, a produção científica, sobretudo em ciências sociais, experimenta uma dicotomia que lhe parece totalmente nociva: os que se consagram ao trabalho científico, com o apoio de métodos sábios, visando seus colegas eruditos, e os que produzem saberes e se engajam na lutas sociais: "para se tornar um sábio engajado, legitimamente engajado, é necessário engajar um saber'. 0 pesquisador não é profeta nem mestre do pensamento. Ele deve escutar, pesquisar, inventar, elaborar conteúdos e meios de ação para poder colaborar com os órgãos que se dão por missão - 'cada vez mais molemente' - resistir ao discurso neoliberal, sustentado em expressões de liberdade e de relaxamento. Ele deve colocar a serviço de todos, numa linguagem simples, as difíceis aquisições da pesquisa, pois freqüentemente é em nome da ciência que se oprime: é hora de acender os 'contrafogos' para resistir à investida neoliberal.

\section{O papel reprodutor dos meios de comunicação}

A mídia também passa a ser alvo das críticas de Bourdieu. A imprensa é considerada como um microcosmo, que tem leis próprias e abriga relações de força específicas. Esse espaço está dominado por forças que vão no sentido contrário ao desvelamento dos mecanismos de reprodução. É no interior desse universo de poder simbólico que precisamos agir e compreender por que é importante desconfiar das aparências, das evidências, do senso comum, de tudo o que é apresentado como natural pelos meios de comunicação. 
Se a polícia e a justiça são o braço visível da repressão simbólica, os intelectuais e jornalistas são freqüentemente sua cabeça. São eles que 'fazem de conta que pensam' e passam seu tempo a atuar na manutenção da ordem moral e simbólica, substituindo a função ideológica e carismática tradicionalmente exercida pelos padres. Seus silêncios, suas omissões, suas abstenções são tão significativos quanto suas ações. Mesmo se dizendo de esquerda, eles vivem como liberais e contribuem de maneira efetiva para a perpetuação e reprodução da ordem.

Ora, os que posam de jornalistas-filósofos são apenas porta-vozes da autoridade estabelecida que, por falta de reflexão, precipitação ou conformismo, estão sempre de acordo e demonstram se sentir muito bem nessa espécie de 'altéia moral', que envolve um profundo sentimentalismo. Eles aparecem como 'intelectuais proletaróides' (para usar a categoria de Weber), dissimulando a ligação entre ação e interesse, entre as práticas dos agentes e os objetivos que perseguem, mais ou menos conscientemente. Cabe ao sociólogo compreender não somente o que se diz na mídia, mas sobretudo o que não se diz, pois em virtude de suas posições, esses profissionais podem negar a hierarquia, em vez de procurar rompê-la.

As críticas exacerbadas de Bourdieu sobre a 'ditadura da mídia' o tornam, paradoxalmente, um ícone midiático. As recorrentes manifestações contra esse universo de poder simbólico - que se constitui num verdadeiro míssil antimíssil ou numa mídia antimídia -, assim como sua concepção de que é no interior desse espaço simbólico que se deve agir, desencadearam uma interminável tempestade nos jornais, impelindo a divulgação de seu trabalho científico e o sucesso espetacular de sua teoria social. Ele defendeu a utilização do potencial do inimigo e, parafraseando Marx, propôs que 'o dominante deva ser dominado por sua dominação': deve-se lutar para a transformação democrática de dentro das instituições antidemocráticas.

\section{Críticas e mal-entendidos a propósito da teoria de Pierre Bourdieu}

No entanto, a teoria social de Pierre Bourdieu é objeto de críticas contundentes e bem ácidas, tanto de seus aliados quanto de seus detratores. Para Brito (2002), seu trabalho "despertou paixões e ódios [na comunidade científica e midiática], mas nunca deixou ninguém indiferente" (p. 5). Sua reflexão sociológica contribuiu para desestabilizar certas práticas intelectuais relativamente cristalizadas. Ele foi permanentemente atacado pelo seu caráter considerado como atrabiliário e por recusar a confrontação de suas teorias com a de outros sociólogos de seu tempo: sempre se negou a responder a questões que, segundo seu ponto de vista, não eram as suas. Entretanto, as críticas que parecem mais relevantes dizem respeito aos aspectos conceituais - e pontuais - de sua teoria e a certos mal-entendidos.

Segundo Lahire (2002), a teoria dos campos - que deveria chamar-se teoria dos campos do poder - não pode constituir uma teoria geral e universal, mas representa uma teoria regional do mundo social. Essa teoria empenha muita energia para iluminar os grandes palcos em que ocorrem os desafios do poder, mas pouca para compreender os que sobem nesses palcos para instalar os cenários, fabricar os equipamentos, varrer o chão e os bastidores, fotocopiar documentos, digitar textos. Nesse sentido, essa teoria mostra pouco interesse pela vida dos agentes fora-do-palco ou fora-do-campo, que lutam no interior do campo. Essa configuração dos campos exclui também as populações sem atividade profissional, principalmente as que comportam certo prestígio (capital simbólico) e podem, portanto, organizar-se em espaços de concorrências e de lutas para a reafirmação desse prestígio específico, podendo se inscrever em múltiplos quadros sociais, privados ou públicos, duráveis ou efêmeros.

A teoria dos campos representa, segundo Lahire (2002), uma maneira de responder a uma 
série de problemas científicos, mas pode tornarse um obstáculo ao conhecimento do mundo social, tanto por não considerar as incessantes passagens operadas pelos agentes (entre os campos nos quais são produtores ou simplesmente consumidores-expectadores e as múltiplas situações que não podem ser referidas a um único campo), quanto por desconsiderar a situação dos que se definem socialmente (e se constituem mentalmente) como estando fora de toda atividade de um determinado campo.

Segundo Sapiro (2003), o conceito de habitus vem designar o sistema de disposições não somente corporais mas também cognitivas, de estruturas estruturantes porque estruturadas, comuns a um grupo social, que vive em condições análogas de existência (classe social ou classe de idade), socializado num mesmo sistema escolar e pertencente a uma mesma geração ou grupo profissional. Essas estruturas, incorporadas sob a forma de disposições (corporais, mentais ou cognitivas), explicam as resistências às mudanças. 0 habitus atribui uma dimensão inventiva a essas disposições e permite, segundo os quadros ou as condições objetivas nas quais são formadas $e$ reativadas, situar-se no mundo social, ajustar-se às suas transformações e projetar-se no futuro.

A propósito da apropriação da herança econômica e cultural, diversos estudos salientam que ela é fruto de um processo emocionalmente complexo e de resultados incertos (há sempre a possibilidade de dilapidação da herança), de identificação e de afastamento em relação aos valores e costumes da família, pois as famílias e os indivíduos não se reduzem à sua posição de classe. 0 pertencimento a uma classe social, traduzido na forma de um habitus de classe que pode se opor ao habitus familiar, pode indicar certas disposições mais gerais, que tenderiam a ser compartilhadas pelos membros da classe, mas dificilmente seriam incorporadas na sua totalidade. Lahire (1999) ressalta que é necessário estudar a dinâmica interna de cada família, as relações de interdependência social e afetiva entre seus membros, para entender o grau e o modo como os recursos disponíveis (os vários capitais e o habitus incorporado pelos pais) são transmitidos aos filhos.

Segundo Casanova (2003), a reflexão de Bourdieu oferece elementos para compreender a questão da 'internacionalidade' como garantia, recurso e arma na luta pela autonomia dos intelectuais. Ele coloca em xeque a teoria da autonomia relativa, presente na idéia de intelectual coletivo, e salienta que o 'jogo' científico é relativamente arriscado: não é fácil enunciar sem eufemismos e sem precauções. Seu trabalho constitui um exemplo inédito e autônomo de construção da autonomia. Casanova considera que um dos principais mal-entendidos a propósito de Bourdieu e de sua imagem pública é o fato de que ele concebe - e representa o papel de intelectual e de sábio inspirando-se mais na postura do artista de vanguarda do que no modelo acadêmico tradicional. Numa das conferências que proferiu (muito profética, o que não era comum), Bourdieu se refere aos 'muros mentais', ressaltando que o estrangeiro aparece geralmente como o lugar da liberdade, da dissidência, da ruptura e que é na luta pela unificação do campo intelectual mundial, e pela remoção de todos os obstáculos à circulação internacional dos procedimentos culturais e de seus produtos, que os intelectuais podem melhor contribuir com o progresso da liberdade e da razão.

$\mathrm{Na}$ opinião de alguns pesquisadores, Bourdieu sempre teve dificuldades para pensar o sujeito reflexivo, ainda que muitas vezes tenha evocado a possibilidade de sair dos determinismos e avançar na direção de um conhecimento sociológico dos processos sociais. 0 que mais escandalizou a intelectualidade foi o fato de que um sábio intervenha tão ativamente no campo político, sobretudo no plano da militância. Segundo Matonti (2003), a sociologia marxista ficou fortalecida com as contribuições teóricas de Bourdieu. A sociologia científica é sem dúvida percebida como uma ameaça aos poderes constituídos, porque propõe uma alternativa completamente credível em termos de explicação do mundo social e, notadamente, dos mecanismos de dominação e de reprodução. 
Carles (2001), motivado pela luta incansável de Pierre Bourdieu contra o 'credo neoliberal' e desejando contemplar seu pensamento 'em movimento' (o que se tornou possível pela realização do filme $A$ sociologia é um esporte de combate), salienta o fato de que ele não cessou de denunciar seus efeitos perversos. Opondo-se à ordem dominante, Bourdieu procurou retraçar as características de um método sociológico único. Para Carles, uma de suas qualidades era a perspicácia de seu conhecimento (que permitia desconfiar das aparências, das evidências, do senso comum e de tudo o que era apresentado como natural pela mídia) e sua capacidade de utilizar as potencialidades dos 'inimigos' para difundir suas teses (a mídia vista como instrumento de difusão do pensamento dominante).

\section{Aporte da obra de Pierre Bourdieu para a sociologia da educação brasileira}

Bourdieu (e seus colaboradores) constrói sua reflexão teórico-crítica a partir da análise do sistema educacional francês, justamente na segunda metade dos anos 1960, quando o Estado alardeava o sucesso das políticas de democratização do ensino. Desde então, ele não deixaria de aprofundar e afinar seus questionamentos e de revelar (com dados incontestáveis) a persistência de desigualdades profundas no que concerne ao acesso, à permanência, às diferenças entre percursos escolares, conforme as classes sociais, o sexo, a origem socioprofissional, o local de moradia. Les Héritiers (1964) e La Reproduction $^{2}$ (1970), obras produzidas juntamente com Passeron, desencadearam um processo de críticas sobre as políticas oficiais de Educação. Recebidas com euforia no campo científico-educacional, essas obras foram rapidamente descartadas sob a alegação de que provocavam um grande pessimismo e muitas incertezas em torno da Educação, conduzindo os agentes educacionais ao imobilismo.

Segundo Pereira, Catani e Catani (2001), até meados de 1970, as referências a Pierre
Bourdieu são incidentais e esporádicas: se nos anos 1960 seu trabalho "causaria certo impacto, embora restrito, na produção sociológica e antropológica universitária, passaria, entretanto, relativamente desapercebido no campo educacional brasileiro, que não responderia com maior entusiasmo à chegada de um sociólogo que, mesmo na França e na Europa, era tido como difícil e não oferecia muitas armas para as lutas acadêmicas da época, voltadas em geral à militância política" (p. 3-4). Os anos 1980 se tornariam decisivos na apropriação dos trabalhos de Pierre Bourdieu, principalmente A reprodução (obra publicada no Brasil em 1975). Desde a publicação, essa obra geraria controvérsias políticas no campo educacional, por estar 'aprisionada na dicotomia muito em voga da reprodução x transformação (que na passagem dos anos 80 para os anos 90 do século XX seria transmutada na dicotomia reprodução x resistência)'. A partir de 1990, a contribuição da teoria de Bourdieu passa a ser mais efetiva, evidenciando novas apropriações conceituais tópicas e do modo de trabalho.

Para Saviani (1987), Bourdieu foi reconhecido como um autor crítico por levar adiante uma importante obra denunciadora, porém politicamente desmobilizadora. Se sua teoria oferece elementos para a crítica da função reprodutora, desempenhada pela escola na sociedade capitalista, não fornece instrumentos para a ação. Assim, a obra de Bourdieu foi destinada a um lugar da análise educacional caracterizado pelo rótulo de 'reprodutivista' ou 'crítico-reprodutivista'.

Segundo Pereira, Catani e Catani (2001), as conseqüências desse viés reprodutivista, que caracterizaram a leitura de uma obra de compreensão difícil, podem ser observadas na pouca atenção ao arcabouço conceitual; na desconsideração de um dos fundamentos da obra, o da existência das mediações e das autonomias relativas entre os campos; no deslocamento da

2. Obra quase sempre classificada como fonte principal da concepção 'reprodutivista'. 
perspectiva sociológica para uma perspectiva ‘sócio-lógica'; na criação de expectativas em torno de propostas pedagógicas, isto é, na ausência de um discurso doutrinal sobre a Educação, o que levou a interpretá-la como uma 'teoria da educação' sem propostas.

Com base num estudo realizado nos mais importantes periódicos brasileiros especializados em Educação ${ }^{3}$, Pereira, Catani e Catani (2001) examinam as leituras da obra de Pierre Bourdieu no campo educacional e indicam que sua recepção foi diversificada. Os pesquisadores registram três formas de apropriação de seu trabalho: uma incidental, caracterizada por referências rápidas, geralmente arroladas na bibliografia, mas não mencionadas no corpo do texto; outra conceitual tópica, caracterizada por uma utilização não sistemática de citações e de conceitos, visando reforçar argumentos ou resultados obtidos e desenvolvidos num quadro terminológico, que nem sempre é o do autor; e uma apropriação do modo de trabalho, caracterizada pelo emprego sistemático de noções e conceitos, demonstrando uma preocupação central com o modus operandi de sua teoria.

Enfim, a obra de Pierre Bourdieu nos remete a novos desafios: torna-se necessário inventar não somente idéias, mas novas formas de intervenção e de ação. Não existem mais deuses, profetas nem mestres pensadores. É necessário inventar modos de organização nos quais se inventem idéias. É necessário servir-se do conhecimento do mundo social para inventar modos de organização, que permitam a invenção coletiva de uma visão nova e realista de economia e de sociedade: não existe democracia efetiva sem um verdadeiro poder contracrítico. 0 intelectual é um desses poderes, e de primeira grandeza.

3. 0 estudo abrangeu 20 revistas (editadas entre 1971 e 1999) e um conjunto de 336 artigos publicados nesses periódicos, dos quais foram analisados 272 artigos (somente os de autores brasileiros), que fazem referência ao sociólogo.

\section{Referências bibliografias}

BOURDIEU, P. Coisas ditas. São Paulo: Brasiliense, 2004.

Contre-feux. Propos pour servir à la résistance contre l'invasion neo-libérale. Paris: Raisons d'Agir, 1998.

Contre-feux 2. Pour un mouvement social européen. Paris: Raisons d'Agir, 2001.

Esquisse pour une auto-analyse. Paris: Raisons d'Agir, 2004.

. Homo academicus. Paris: Minuit, 1998.

La distinction. Paris: Minuit, 1979.

La misère du monde. Paris: Seuil, 1993.

. La noblesse d’État; grandes écoles et esprit de corps. Paris: Minuit, 1989.

Méditations pascaliennes. Paris: Seuil, 1997.

0 poder simbólico. Rio de Janeiro: Bertrand Brasil, 2001.

Raisons pratiques; sur la théorie de l'action. Paris: Seuil, 1994.

Sur la televisión; suivi de l'emprise du journalisme. Paris: Raisons d'Agir, 1996.

BOURDIEU, P.; PASSERON, J.-C. A reprodução: elementos para uma teoria do sistema de ensino. Rio de Janeiro: Francisco Alves, 1975. 
BRIT0 A. X. Rei morto, rei posto? As lutas pela sucessão de Pierre Bourdieu no campo acadêmico francês. Revista Brasileira de Educação, n. 19, p. 5-19, jan/fev/mar/abr. 2002.

CARLES, P. La sociologie est un sport de combat. Paris: 2001. (Filme)

CASANOVA, P. La revue Líber: réflexions sur la notion "d'autonomie relative" dans l'œuvre de Pierre Bourdieu. Colloque International: hommage à Pierre Bourdieu. Paris. jan/2003 (mimeo.).

CATANI, A. M. A sociologia de Pierre Bourdieu (ou como um autor se torna indispensável ao nosso regime de leituras). Educação \& Sociedade, n. 78, p. 57-75, abr/2002.

LAHIRE, B. Pour une sociologie à l'état vif. In: . Le travail sociologique de Pierre Bourdieu: dettes et critiques. Paris: La Découverte, 1999, p. 5-20. Reprodução ou prolongamentos críticos? Educação \& Sociedade, n. 78, p. 37-55, abr/2002.

LUCIANO T. A República de Pierre Bourdieu (entrevista). Revista República. A Revista do Site Primeira República, fev/2002, ano 06, n. 64, p. 48-51.

MATONTI, F. O julgamento da sociologia pelos intelectuais comunistas. Colloque International: hommage à Pierre Bourdieu. Paris, jan/2003 (mimeo.).

MENEZES NeTO, A. J. Produções e leituras de Pierre Bourdieu. Presença Pedagógica, v. 8, n. 44, mar/abr/2002, p. 34-37.

NOGUEIRA, C. M. M.; NOGUEIRA, M. A sociologia de Pierre Bourdieu: limites e contribuições. Educação \& Sociedade. Revista Quadrienal de Ciência da Educação, n. 78, Abr/2002, p. 15-36.

ORTIZ, R. A procura de uma sociologia da prática. In: (Org.). Pierre Bourdieu. São Paulo: Ática, 1994, n. 39, p. 7-37. (Coleção Grandes Cientistas Sociais)

PEREIRA, G. R. M.; CATANI, D. B.; CATANI, A. M. As apropriações da obra de Pierre Bourdieu no campo educacional brasileira. Revista Brasileira de Educação. São Paulo: ANPEd, n. 17, p. 63-85, maio/ago./2001. Disponível em: <http://redalyc.uaemex.mx/ redalyc/pdf/275/27501706.pdf>. Acesso em: 01/07/2005. (www.anped.org.br).

PINTO, L. Derrida, Foucault, Bourdieu. Colloque International: hommage à Pierre Bourdieu. Paris, jan/2003 (mimeo.).

SAPIRO, G. La genèse de la théorie de l'habitus. Colloque International: hommage à Pierre Bourdieu. Paris, jan/2003 (mimeo.).

SAVIANI, D. Educação: do senso comum à consciência filosófica. São Paulo: Cortez, 1987.

THOMPSON, J. B. Préface à l'édition anglaise. In: BOURDIEU, P. Language et pouvoir symbolique. Paris: Seuil, 2001, p. 7-51.

TRIGO L. A república de Pierre Bourdieu (entrevista). Revista República. A Revista do Site Primeira República, ano 6, n. 64, fev/2002, p. $48-51$

Recebido em 07.02.06

Modificado em 21.08.06

Aprovado em 01.09.06

Ione Ribeiro Valle é doutora em Ciências da Educação pela Faculdade de Ciências Humanas e Sociais - Sorbonne, Universidade René Descartes - Paris V - e professora da Universidade Federal de Santa Catarina - UFSC - Centro de Ciências da Educação - CED. 